\title{
Research on the Willingness and Demand of Labor Transfer Training in New-type Rural Community Based on Survey Data
}

\author{
Xian'gang $\mathrm{Hu}$ \\ College of Management \\ North China University of Science and Technology \\ Tangshan, China 063000
}

\author{
Julu Yuan \\ The Department of Social Science \\ North China University of Science and Technology \\ Tangshan, China 063000
}

\begin{abstract}
Labor transfer training in new-type rural community is an important part of rural labor transfer training and plays an important role in promoting rural labor transfer employment, increasing community residents' income, promoting China's urbanization process and rural revitalization. The current training of labor transfer in newtype rural communities has the problems of mismatch of supply and demand and imbalance of supply structure, resulting in poor training effect, which is not conducive to the employment of labor transfer in new-type rural communities and the promotion of urbanization. Therefore, the willingness and demand of labor transfer training in new-type rural communities has become an important research content. According to the field survey data of three typical new-type rural communities in Hongzhou community, Huazhong community and Nanbei community in Qihe county, the willingness of labor training is analyzed, and the influencing factors of the willingness of training were analyzed with the binary Logistic regression model and the demand for labor transfer training was analyzed. The study found that age, education level, occupation, family annual income and whether to participate in training and other factors affect the training willingness and the demand for labor transfer training in newtype rural community are diversified. Finally, it is believed that analyzing the training willingness and demand of the newtype rural community labor transfer is an important prerequisite to solve the problems of the current training supply and demand dislocation and supply structure imbalance. Empirical research represented by practical investigation and statistical analysis is helpful to propose policy recommendations for new type of rural community labor transfer training. It is the most important research to give the way or method to solve the problems in the training of newtype rural community labor transfer.
\end{abstract}

Keywords-new-type rural community; labor transfer training; willingness and demand for training; binary logistic regression model; new-type urbanization

\section{INTRODUCTION}

According to the existing researches, new-type rural community can be defined as a new concentrated residential production and living community, breaking through the administrative and village boundaries of the original rural community, merged from several original administrative villages under uniform planning of the government and integrated with uniformly constructed housing and public service facilities. [1] The construction of new-type rural communities is a new social life form created by the Chinese government in rural area based on the current urbanization process to share the development achievements with farmers. In terms of residential production and living styles and public service level and so on, such community is far superior to traditional rural community. The construction and development of new-type rural community has become an important part of China's new urbanization course, opening up a new road for rural labor transfer and becoming an important way to promote China's new urbanization. New urbanization is the urbanization of "people". Population urbanization is the core of new urbanization and economic urbanization is an important support for new urbanization. [2] People and economy are the key points to be paid attention to in the construction of new-type rural community. However, in the current process of labor transfer in new-type rural communities, there are many problems such as paying more attention to spatial transfer of rural labor force but less to their adaptability, the low vocational skill level of transferred rural labor force, insufficient non-agricultural employment, low agricultural production level and insufficient recognition and transforming of the "citizen" identity of residents in new-type rural community.

Providing rural labors with applicable education and training is always an important measure taken by the government to deal with the problems appeared in the process of rural labor transfer. Chinese government has implemented a series of measures for rural labor education and training for years, such as "Sunshine Project", "Rain Project", and "Spark Program" and so on. In recent years, both the "agricultural supply side structural reform" and "rural revitalization strategy" proposed by the central government have made important instructions for rural labor education and training. The state issued a series of related policies and regulations to support the training and achieved certain effect. However, the current labor transfer training in new-type rural community has the problems such as mismatched training supply and demand and unbalanced supply structure, resulting in poor training effect. It is not 
conducive to the promotion of new-type rural community labor transfer and urbanization. Therefore, researching the willingness of and demand for labor transfer training in newtype rural communities has become an important research subject.

Based on the primary data and related data collected from the field survey in three typical new-type rural communities such as Hongzhou Community, Huazhong Community and Nanbei Community in Qihe County, this paper researches the current willingness and demand of labor transfer training in new-type rural communities and proposes policy suggestions for labor transfer training in new-type rural community so as to promote solving problems existing in current training and boost the urbanization progress in China.

\section{LITERATURE REVIEW}

It is a consensus of scholars both at home and abroad to improve the quality and vocational skills of rural labors and promote the transfer and employment of rural labors through relevant training.

Adam Smith believed that people's working ability and level re constrained by their extent of proficiency in labor skills. Therefore, it is necessary to receive relevant training in order to master certain working skills, but it is needed to spend certain time and money on the training. [3] Schultz T.W believed that capital includes the factors of object and the factors of human beings, and human capital is the main source of agricultural economic growth. The formation of human capital investment includes education, in-service training and health conditions. Wherein, education is more important. [4] The above two scholars affirmed the role of education and training in human development. Revera W.M [5], Paul Bennel [6] and et al made a research on the problems existing in agricultural education courses such as the dis-accordance between the training content and actual condition and the incomplete training course content. Zinnah M.M [7] studied the training demand of rural labor force, evaluated the training effect, and also pointed out the problems existing in the training and gave the solution for the problems in relevant education and training.

With the continuous development and progress of the society, rural labor force has a strong demand for improving self-quality and ability in order to meet the needs of the society and is eager to improve their own quality through training so as to smoothly realize the transfer of employment. By research, Wu Sufang and Wang Yulan found that China's rural labor transfer training may fall into the cycle of "excessive" and "not excessive" demands and "sufficient" and "in-sufficient" supplies. The cycle practically indicated the problems existing in the demand and supply of rural labor transfer training in China. [8]

Based on the data collected from migrant workers in Ningxia in aspects of gender, monthly income, training expense, awarded training certificate and certificate grade and so on, Shi Donghui and Shi Dongmei analyzed the factors affecting the rural labor transfer training needs of rural area in Ningxia and put forward corresponding policy suggestions. [9] Based on an investigation on landless farmers in Guangdong province, Pan Guanghui studied the training needs of rural laborers. As a result, he found that the overall lag of training supply restricted the demand for rural labor transfer training. [10]

In summary, it has become a broad consensus to improve the quality of rural labors and promote their smooth transfer through training. In order to truly improve the quality of rural labor force, the top priority in research shall be given to making clear the rural labors' transfer training willingness and training need. This paper explores the transfer training willingness and demands of labors in new-type rural communities by conducting an empirical research based on the field survey data collected from new-type rural communities in order to make some contribution both in theory and practice.

\section{SAMPLE DATA COLLECTION AND SAMPLE CHARACTERISTICS}

\section{A. Data Collection}

In this study, Hongzhou Community in Liuqiao Town, Huazhong Community in Huadian Town and Nanbei Community in Yanbei Street of Qihe County were selected as three typical new-type rural communities and were respectively distributed with 50,80 and 70 questionnaires based on the populations of each community (total: 200 questionnaires). Since each questionnaire was completed under the guidance in person, 200 questionnaires were returned and the effective recovery rate was $100 \%$. After the questionnaire was collected, the data was sorted, entered into the computer, and analyzed by using SPSS 17.0 software. The primary data obtained through the survey is an important realistic basis for this study.

\section{B. Sample Characteristics}

1) Community labors' personality characteristics: Among the 200 respondents, there were 88 males and 112 females, respectively accounting for $44 \%$ and $56 \%$, which is in line with the situation of much male labor outflow in the community labor force. The average age was 40.43 years old, of which there were 135 laborers of 31 to 50 years old, accounting for $67.5 \%$. This age group of laborers was young adults, and was the main force of production. Hence, relevant training should pay more attention to their needs. In terms of education level, there were 117 persons received junior high school education, accounting for $58.5 \%$, which was basically in line with the current level of education of rural laborers in China. In terms of marital status, there were 7 unmarried people, accounting for 3.5\%; 193 people are married, accounting for $96.5 \%$. By analyzing the questionnaire data, it is found that young men and women over the age of 23 have married basically, and there are few rural laborers who are unmarried and do not go to school. It can be seen that the residents of the new-type rural community still have a relatively traditional concept of marriage, namely to establish a family and pursue a stable life. From the work engaged in by the labor force in new-type rural communities, most of them are workers and farmers, accounting for $56.5 \%$ and 
$33.5 \%$ respectively. In terms of personal monthly average income level, those whose income is within 1000 3000 Yuan accounts for $62 \%$ and those not more than 1000 Yuan accounts for $23 \%$. It can be seen that currently the general income level of labor force in new-type rural communities is not high; and the income of most residents is within 1000 3000; the families having total annual income less than 10,000 Yuan accounts for $8 \%$, and those within $10,000 \sim 30,000$ Yuan accounts for $44 \%$ (52\% in total); the familys at low income level are in majority and those more than 50,000 Yuan only accounts for $7.5 \%$. From the data of personal monthly average income and family annual total income, it can be seen that the overall income level is not high, but their incomes has a polarization trend.

2) Satisfaction with current work: As shown in "Table I", among labor forces in new-type rural communities, those who are satisfied with their current works accounts for $60 \%$ and those not that satisfied and dissatisfied accounts for $40 \%$. In fact in the field survey, the community residents complained about the current work and income levels somewhat. Those who have low income or engage in agriculture have low satisfaction. And those who have relatively high income have high satisfaction.

TABLE I. WORK SATISFACTION

\begin{tabular}{|c|l|l|}
\hline Frequency & \multicolumn{1}{|c|}{ Percentage } \\
$\begin{array}{c}\text { Very satisfied } \\
\text { Satisfied }\end{array}$ & 4 & 2.0 \\
\hline Not so satisfied & 116 & 58.0 \\
\hline $\begin{array}{c}\text { Very dissatisfied } \\
\text { Total }\end{array}$ & 91 & 35.5 \\
\hline
\end{tabular}

3) Improvement extent of family economic status: As shown in "Table II", in terms of the improvement extent in economic conditions after transforming the traditional rural community into new-type rural community, those who indicate that it becomes much better and a little good accounts for $27.5 \%$, those holding that there is no change accounts for $60.5 \%$ and those indicating that it becomes a little bad accounts for $12 \%$. This shows that compared with the traditional rural production and living, the income levels of residents were not increased accordingly after village combination and centralized residence. The production mode of labor forces in community needs to be changed, and their employment skills and professional quality need to be improved.

TABLE II. EXTENT OF ECONOMIC IMPROVEMENT

\begin{tabular}{|c|l|l|}
\hline & \multicolumn{1}{|c|}{ Frequency } & \multicolumn{1}{c|}{ Percentage } \\
\hline Much better & 8 & 4.0 \\
\hline A little good & 47 & 23.5 \\
\hline No change & 121 & 60.5 \\
\hline A little bad & 24 & 12.0 \\
\hline Total & 200 & 100.0 \\
\hline
\end{tabular}

\section{ANALYSIS ON THE TRANSFER TRAINING WILLINGNESS OF LABORERS IN NEW-TYPE RURAL COMMUNITIES AND THE INFLUENCING FACTORS}

The analysis on the willingness of labor transfer training in new-type rural communities is to analyze whether labor forces in the new-type rural community is willing to or needs to receive training. The factors affecting community labor forces' training willingness are analyzed by selecting the variables of labor forces in the community such as their personal characteristics, satisfaction with current work, extent of family economic improvement, and whether they once participated in relevant training or not and using binary logistic regression model.

\section{A. Training Willingness Analysis}

As shown in "Table III" based on data collected from field surveys, among the 200 samples, 146 persons indicated that they were willing to participate in the training, accounting for $73 \%$; 54 persons said that they were unwilling to participate in the training or it depends, accounting for $27 \%$. As can be seen from the results, the vast majority of people in the community are willing to participate in the training, and have strong requirement for the training.

TABLE III. TRAINING WILLINGNESS

\begin{tabular}{|c|l|l|}
\hline & \multicolumn{1}{|c|}{ Frequency } & \multicolumn{1}{c|}{ Percentage } \\
\hline Willing & 146 & 73 \\
\hline Unwilling & 54 & 27 \\
\hline Total & 200 & 100.0 \\
\hline
\end{tabular}

\section{B. Analysis on Factors Affecting the Training Willingness}

It is to analyze and determine the factors having effect on the willingness of the community labor force. In the supply training, it is suggested to pay attention to the different training demands of the community labor forces due to their differences in individual and family and other aspects, so that the training supply meets the relevant demand.

Model setting: This paper analyzes the willingness of labor forces to receive transfer training in new-type rural communities. It is certain that there are many influencing factors, but there are only two possible results, namely, willing to participate and unwilling to participate. This is the binary variable of $[1,0]$. The willingness of labor forces in new-type rural community to select participating in the training is a discrete choice problem. Hence, the probability model may be the ideal choice. Binary Logistic regression model is a very effective model for conducting regression analysis on the dependent variable which is binary categorical variable.

Basic form of the logistic regression model:

Assumption: dependent variable is $\mathrm{y}$, and the value is (1, $0)$, wherein " 1 " indicates that the event occurred and " 0 " indicates that the event did not occur. The $\mathrm{m}$ independent variables having effect on $\mathrm{y}$ are respectively recorded as: $x_{1}, x_{2}, x_{3} \ldots, x_{m}$. The occurrence probability of the studied event is recorded as $p_{i}$. 


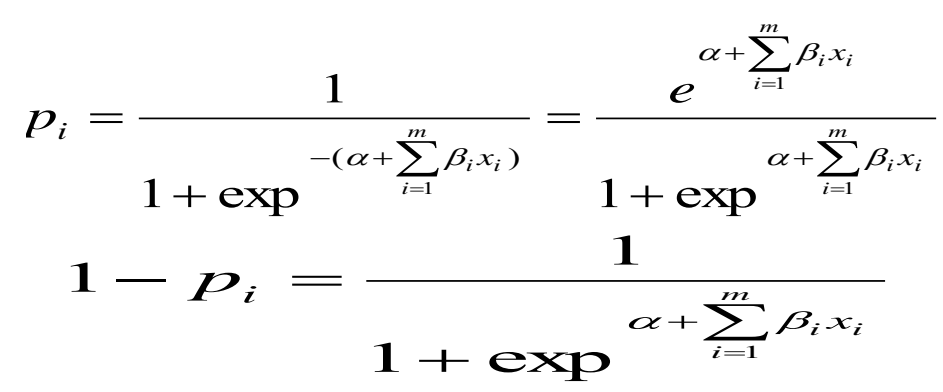

Wherein, $p_{i}$ indicates the probability of occurrence of an event in the $i$ th observation and $1-p_{i}$ indicates the probability that the event does not occur in the $i$ th observation. $x_{i}$ is an independent variable function. Conducting logarithmic transformation on $p_{i} / 1-p_{i}$, you can get the linear model of logistic regression:

$$
\ln \left(\frac{p_{i}}{1-p_{i}}\right)=\alpha+\sum_{i=1}^{m} \beta_{i} x_{i}
$$

Wherein, $\alpha$ is the intercept term, and $\beta_{i}$ is the regression coefficient of the influencing factors.

In this research, the willingness of labor forces in community to participate in the training is recorded as dependent variable $\mathrm{y}$, taking the value of $(1,0)$, the willingness to participate in the training is defined as $y=1$, and the unwillingness or depending on circumstances is defined as $y=0$. In this research, ten variables are selected as independent variables such as gender $\left(x_{1}\right)$, age $\left(x_{2}\right)$, education level $\left({ }^{x_{3}}\right)$, marital status $\left({ }^{x_{4}}\right)$, occupation $\left({ }^{x_{5}}\right)$, personal monthly income $\left({ }^{x_{6}}\right)$, family annual total income $\left({ }^{x_{7}}\right)$, current work satisfaction $\left({ }^{x_{8}}\right)$, improvement extent of family economic status ( $x_{9}$ ) and whether they once participated in relevant training or not $\left(x_{10}\right)$. Detailed variable characteristics, descriptive statistics and expected effect direction of the sample are as shown in "Table IV".

A new-type rural community labor transfer training willingness model is created as follows on the basis of the above-defined dependent variables and independent variables:

$$
\ln \left(\frac{p_{i}}{1-p_{i}}\right)=\beta_{0}+\beta_{1} x_{1}+\beta_{2} x_{2}+\beta_{3} x_{3}+\ldots \beta_{i} x_{i}+\varepsilon_{i}
$$

Wherein, $p_{i}$ indicates the probability that the new-type rural community laborers are willing to participate in the training; $\beta_{i}$ represents the regression coefficient of independent variable; ${ }^{x_{i}}$ represents independent variable and the $i_{\text {th kind of influencing factor; }} \beta_{0}$ represents the regression intercept,; and $\varepsilon_{i}$ represents random error.

\begin{tabular}{|c|c|c|c|c|}
\hline Variable & Definition of variable & $\begin{array}{c}\text { Avera } \\
\text { ge }\end{array}$ & $\begin{array}{l}\text { Standard } \\
\text { deviation }\end{array}$ & $\begin{array}{l}\text { Expected } \\
\text { direction }\end{array}$ \\
\hline $\begin{array}{l}\text { Interpreted variables: willingness } \\
\text { to participate in training }\end{array}$ & Willing $=1$; not willing $=0$ & 0.73 & 0.45 & \\
\hline Interpreting variable: gender & Male $=1 ;$ female $=2$ & 1.56 & 0.50 & $+/-$ \\
\hline Age & Actual age of the respondent & 40.43 & 9.39 & - \\
\hline Education level & $\begin{array}{l}\text { Elementary school and below }=1 ; \text { junior high } \text { school }=2 \text {; } \\
\text { high school }=3 \\
\text { College and above }=4\end{array}$ & 2.05 & 0.69 & + \\
\hline Marital status & Unmarried $=1 ;$ married $=2$ & 1.97 & 0.18 & $+/-$ \\
\hline Occupation & Farmer $=1 ;$ worker $=2 ;$ individual operator $=3 ;$ other $=4$ & 1.77 & 0.63 & + \\
\hline Personal monthly income & $\begin{array}{l}\text { Less than } 1000 \text { Yuan }=1 ; 1001 \sim 2000 \text { Yuan }=2 \\
2001 \sim 3000 \text { Yuan=3; more than } 3000 \text { Yuan }=4\end{array}$ & 2.37 & 1.00 & + \\
\hline Family annual total income & $\begin{array}{l}\text { Less than } 10,000 \text { Yuan }=1 ; 10,000 \sim 30,000 \text { Yuan }=2 ; \\
30,000 \sim 50,000 \text { Yuan }=3 ; \text { more than } 50,000 \text { Yuan }=4\end{array}$ & 2.48 & 0.75 & + \\
\hline Current work satisfaction & $\begin{array}{l}\text { Very satisfied }=1 \text {; satisfied }=2 ; \text { not so satisfied }=3 \text {; very } \\
\text { dissatisfied }=4\end{array}$ & 2.43 & 0.61 & $+/-$ \\
\hline $\begin{array}{l}\text { Extent of improvement in family } \\
\text { economic conditions }\end{array}$ & $\begin{array}{l}\text { Much better }=1 ; \text { a little good }=2 ; \text { no change }=3 \\
\text { A little bad }=4\end{array}$ & 2.80 & 0.7 & $+/-$ \\
\hline $\begin{array}{l}\text { Have you ever received relevant } \\
\text { training? }\end{array}$ & Yes $=1 ;$ no $=2$ & 1.82 & 0.38 & + \\
\hline
\end{tabular}

TABle IV. VARiable Characteristics, Descriptive Statistics AND EXPeCted EFFeCt Direction of the SAmple 
1) Logistic regression results: This paper makes binary logistic regression analysis on the collected data by using spss17.0 statistical software. In the regression, the "backward: Wald" method is used. First, all independent variables are selected into the model, and variables are eliminated according to whether the probability value of the Wald statistic is greater than a given significant level.

Goodness of fit of the model: the logarithmic likelihood value of -2 is 98.68, Cox\& Senll $R^{2}$ is 0.50 , and Nagelker $k e R^{2}$ is 0.71 . From this point of view, the model has a good fitness.

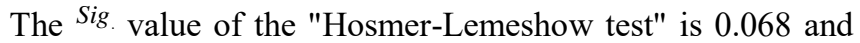
is greater than the specified significance level 0.05 . Accepting the null hypothesis model can fit the data well. Therefore, it can be seen that the model has a good goodness of fit. The model's prediction accuracy rate is $90.5 \%$. This indicates that the model's prediction effect is good and the model is relatively stable (see "Table V").

As can be seen from the independent variable regression results, the variables in the equation are: age $\left(x_{2}\right)$ passed the test at the $1 \%$ significance level. The independent variables such as the education level $\left({ }^{x_{3}}\right)$, occupation $\left({ }^{x_{5}}\right)$, and family annual total income $\left(x_{7}\right)$ all passed the test at the significance level of $5 \%$, and whether they ever participated in relevant training or not $\left(x_{10}\right)$ passed the test at the significance level of $10 \%$. This indicates that these factors have an impact on and is greatly related to the transfer training willingness of labor forces in new-type rural communities (see "Table VI").

The variables that are not in the equation are gender $\left({ }^{x_{1}}\right)$, marital status $\left({ }^{x_{4}}\right)$, personal monthly income $\left({ }^{x_{6}}\right)$, current work satisfaction $\left(x_{8}\right)$, and improvement extent in family economic status $\left({ }^{x_{9}}\right)$. The Sig. values of these independent variables were all greater than the significance levels of $5 \%$ and $10 \%$ and were eliminated from the equation (see "Table VI"). It shows that these factors have little effect on the transfer training willingness of labor forces in new-type rural communities.

TABLE V. VARIABLES IN THE EQUATION

\begin{tabular}{|l|l|l|l|l|}
\hline \multicolumn{1}{|c|}{ Independent variable } & \multicolumn{1}{c|}{ B } & \multicolumn{1}{c|}{ Wals } & Sig. & Exp (B) \\
Age $\left(x_{2}\right)$ & $-.17^{* * *}$ & 14.86 & .00 & .84 \\
\hline Education level $\left(x_{3}\right)$ & $1.04^{* *}$ & 4.23 & .04 & 2.83 \\
\hline Occupation $\left(x_{5}\right)$ & $1.09^{* *}$ & 5.62 & .02 & 2.99 \\
\hline Family annual total income $\left(x_{7}\right)$ & $1.01^{* *}$ & 3.88 & .04 & 2.74 \\
\hline Whether they ever participated in any relevant training or not $\left(x_{10}\right)$ & $1.10^{*}$ & 3.21 & .07 & 3.01 \\
\hline Constant & .69 & .053 & .818 & 1.99 \\
\hline $\begin{array}{l}\text { Logarithmic likelihood value of }-2 \\
\text { Cox \& Senll } R^{2}\end{array}$ & & & 98.68 & \\
\hline Nagelker $k e R^{2}$ & & & .71 & \\
\hline = Hosmer and Lemeshow test $=$ & & & .068 & \\
\hline Prediction accuracy rate & & & $90.5 \%$ & \\
\hline
\end{tabular}

$* * *$ and *** respectively represent significant levels of $10 \%, 5 \%$ and $1 \%$

${ }^{\mathrm{b} .} \mathrm{B}$ is the value of the B test statistic, Wald is the chi-square test statistic, Sig. is the corresponding test value ${ }^{p}$ of the Wald chi-square value at the corresponding degree of freedom, and Exp(B) is the index of the B-

TABLE VI. VARIABLES NOT IN THE EQUATION

\begin{tabular}{|l|l|l|l|}
\hline \multicolumn{1}{|c|}{ Independent variable } & Score & df & Sig. \\
\hline Gender $\left(x_{1}\right)$ & .01 & 1 & .94 \\
\hline Marital status $\left(x_{4}\right)$ & .50 & 1 & .48 \\
\hline Personal monthly income $\left(x_{6}\right)$ & .05 & 1 & .83 \\
\hline Current work satisfaction $\left(x_{8}\right)$ & .86 & 1 & .36 \\
\hline Improvement extent in family economic status $\left(x_{9}\right)$ & 1.22 & 1 & .27 \\
\hline
\end{tabular}

df is the degree of freedom, and Sig. is the test value $P$ when Wald chi-square value is at the corresponding degree of freedom. 
2) Explanation of the test results: As can be seen from the regression results, the age is significant and negatively correlated at the level of $1 \%$, which is consistent with the expected results. This indicates that with respect to the newtype rural community labor transfer training willingness, the larger age the laborer is in, the less they are willing to receive such training. Among the 200 samples, 54 samples were unwilling to receive the training, of which 29 samples of 50 60 years old were unwilling to receive training and 50 samples of $40 \sim 60$ years old were unwilling to receive training. This is consistent with the findings in the field survey. The older labor forces, especially the more than 50year-old labor force, believe that "when they are older, no one would employ them so that they cannot apply what they learnt into work" so they are less willing to receive training.

The level of education is significant at the level of 5\% and is positively correlated and consistent with the expected results. This indicates that the higher education level the sample has, the more they are willing to receive training. Among the 200 samples, 146 samples were willing to receive training, of which 140 samples of junior high school and above education level were willing to receive training and only 6 samples of primary school and lower education level were willing to receive training, accounting for only $4.1 \%$ of the total number of samples willing to receive training. There were 54 people unwilling to receive training, of which 33 people were of primary school and lower education level, accounting for $61.1 \%$ of the total number of people unwilling to receive training. The labor forces having lower education level did not have sufficient recognition on the change brought to their income and life by receiving the training and the value of improving their own occupational quality. They did not understand relevant training policies of the country and their development pursuit is limited to the field of their current life and occupation. However, labor forces having higher education level were more open-minded and more capable of accepting new things, had the willingness to pursue self-improvement, and expected to crease income.

The occupation is significant at the level of $5 \%$ and is positively correlated and consistent with the expected results. It shows that people engaging in different jobs have different willingness to receive training. The more people engage in non-agricultural work, the more they are willing to participate in training. Among the 146 people willing to receive training, there were 120 people working and selfemployed, accounting for $82.2 \%$, and only 25 people engaging in agriculture, accounting for $17.1 \%$. Among the 54 people unwilling to receive training, 42 people were farmers, accounting for $77.8 \%$. Over field visits, it was found that the thought of labor forces in new-type rural community was relatively simple. They still focused on farmland. They might feel at ease if only they have farmland. They were easy to be satisfied and content with things as they are. They were obviously constrained by traditional individual farmer's thinking. Moreover, the agricultural workforce had insufficient understanding of the training policies and values so that they had not that strong willingness to participate in the training because there were no or few agricultural and production technical training organized in community in addition to the lack of publicity. However, the labor forces engaging in industry or project or self-employed had high requirement for the development of themselves as they have more opportunities to contact with different people, obtain new social information and broaden their visions. Therefore, in training organizations and propaganda, it is necessary to pay attention to the labor force engaging in agriculture to fully mobilize their enthusiasm.

The family annual total income is significant at the level of $5 \%$ and is positively correlated and consistent with the expected results. It indicates that the more family annual total income they have, the more they are willing to participate in the training. Among the 146 samples willing to receive training, 92 persons have total annual income of more than 30,000 Yuan and are willing to receive the training, accounting for $63 \%$. Labor forces of high family annual total income in new-type rural community are generally more optimistic about the future. They are confident and interested in expanding their abilities and want to improve themselves in order to obtain more income and development. And those of low family annual total income may be worried about the training costs. Even if they are free to receive the training, they may also need to consider the time cost. Most people may worry about wasting time but learn nothing. They think that it is not as good as doing well in their agricultural work. It is their risk prediction that restrains their willingness selection.

The index of whether they ever participated in relevant training or not is significant at the level of $10 \%$ and is positively correlated and consistent with the expected results. It shows that those who once participated in training are more inclined to be reluctant to receive the training. From the previous analysis of the current training status, it can be explained that 35 of the 200 samples surveyed have ever received training. Of which, $62.8 \%$ of them think that there is no significant change in income after receiving the training; $40 \%$ of them think that the effect is general in common sensation after receiving the training; and $45.7 \%$ of them think that there is not that large and even no effect. The community laborers who have participated in the training have a personal experience in the training process and results. They think that they spend time on it but fail to learn some practical technology and the training fails to help them become better in employment or income. So, they may be prudent to look upon the training and don't have strong willingness to receive the training.

\section{TRAINING DEMANDS ANALYSIS}

On the basis of understanding the willingness of labor transfer training in new-type rural community and its influencing factors, it is necessary to further analyze the requirements of labor forces for training content, training method, training time, training costs, etc., so as to help providing targeted training. 


\section{A. Demand for Training Content}

In demand for training content as shown in "Table VII", among the 200 samples, 63 people accounting for $31.5 \%$ (taking the largest proportion) have demands for vocational training in industries such as manufacturing, architecture, community household service, catering and entertainment industries. 56 people accounting for $28.0 \%$ choose agricultural production technology training. This shows that labor forces' demand for agricultural production technology training is also very rushing. 41 people select entrepreneurship guidance and business management training, accounted for $20.5 \%$. It can be seen that with the development of production and under the influence of national innovation and mass entrepreneurial policies, the awareness of entrepreneurship of labor forces in new-type rural communities is gradually awakened. There are 19 people selecting agricultural management training, accounting for $9.5 \%$. The community labor force is still limited to small-scale agricultural production and lacks attention to the scale operation and management of modern agriculture. However, some laborers with open minds and high education level have training needs for agricultural operation and management. This indicates that modern agriculture has a tendency to good prospect. 14 people have demand for training on common sense of life in community such as community, security, environment and sanitation, culture and entertainment, catering and recreation, etc., accounting for $7.0 \%$. Seven people select training on laws and regulations in aspects such as homestead reclaiming, land contracting, property division and inheritance, accounting for $3.5 \%$. From these two aspects, the community labor force still more concern about increasing income and lack of attention to the adaptation to community life and the maintenance of their own rights and interests. However, in the long run, training on common sense of life in community and training on laws and regulations are very important. It can drive labor forces in community to better adapt to centralized residence life in community, promote the various qualities of them and promote the transformation of their "citizen" identity and psychological recognition while their material demands are met.

TABLE VII. DEMAND FOR TRAINING CONTENT

\begin{tabular}{|l|l|l|}
\hline \multicolumn{1}{|c|}{ Frequency } & Percentage \\
\hline $\begin{array}{l}\text { Agricultural production technology training in aspects of } \\
\text { planting, breeding, etc. }\end{array}$ & 56 & 28.0 \\
\hline $\begin{array}{l}\text { Skills training in industries such as manufacturing, } \\
\text { architecture, community household service, catering and } \\
\text { entertainment }\end{array}$ & 63 & 31.5 \\
\hline Agricultural operation and management training & 19 & 9.5 \\
\hline $\begin{array}{l}\text { Entrepreneurship guidance and business operation and } \\
\text { management training }\end{array}$ & 41 & 20.5 \\
\hline $\begin{array}{l}\text { Training on common sense of life in community such as } \\
\text { community, security, environment and sanitation, culture } \\
\text { and entertainment, catering and recreation, etc. }\end{array}$ & 14 & 7.0 \\
\hline $\begin{array}{l}\text { Training on laws and regulations in aspects of homestead } \\
\text { replacement, land contracting, property division and } \\
\text { inheritance }\end{array}$ & 7 & 3.5 \\
\hline Total & 200 & 100.0 \\
\hline
\end{tabular}

\section{B. Demand for Training Method}

In demand for training method, 115 of the 200 samples select practical training, accounting for 57.5\%. Most community laborers believe that the combination of learning theory and practical operation is an effective way to learn knowledge and skills. 48 people chose face-to-face lectures, accounting for $24.0 \%$. They think that listening in classroom and interacting with teachers is a good way to learn. 37 people chose to study through the Internet and $\mathrm{TV}$, accounting for $18.5 \%$. They believe that training on knowledge, experience and management can be learnt through the Internet and TV (see "Table VIII"). It can also be seen that the demand for training methods of labor forces in new-type rural community is also diversified.
TABLE VIII. DEMAND FOR TRAINING METHOD

\begin{tabular}{|l|l|l|}
\hline & Frequency & Percentage \\
\hline Practical training & 115 & 57.5 \\
\hline Face to face teaching & 48 & 24.0 \\
\hline Learning on Internet and TV & 37 & 18.5 \\
\hline Total & 200 & 100.0 \\
\hline
\end{tabular}

\section{Demand for Training Cycle}

From the point of training time, according to the field survey, it is known that the training time is mostly concentrated in the evening, when the community labor is off work or after the end of the agricultural busy. For the training cycle, among the 200 samples, 89 people choose to receive training for a period within 1 month, accounting for $44.5 \%$ (the highest proportion); 71 people choose to receive training for a period within 1 3 months, accounting for $35.5 \%$; 38 people choose to receive training for a period $4 \sim 6$ 
months, accounting for $9.0 \%$; 2 people choose to receive training for a period of more than 6 months, accounting for $1.0 \%$ (see "Table IX"). Over field survey, it is learned that the current labor transfer training of new-type rural communities is mostly irregular short-term training and most of the training time is after work at night and after the end of the agricultural busy. The trained labor forces feel that the training effect is not great, and it was not available to master a technology and did not help them much. Therefore, the training time of community labor force should be relatively fixed and continuous.

TABLE IX. DEMAND FOR TRAINING CYCLE

\begin{tabular}{|l|l|l|}
\hline & Frequency & Percentage \\
\hline Within 1 month & 89 & 44.5 \\
\hline $1 \sim 3$ months & 71 & 35.5 \\
\hline $4 \sim 6$ months & 38 & 19.0 \\
\hline More than 6 months & 2 & 1.0 \\
\hline Total & 200 & 100.0 \\
\hline
\end{tabular}

\section{Demand for Training Cost}

Training cost is always a matter of great concern for rural labor forces in considering whether to participate in the training or not. Among the 200 samples in this survey, 112 people hope that the training is not more than 100 Yuan, accounting for $56.0 \%$. Most of them hope that the training is provided free of charge. 24 people can receive training at a cost of 100 300 Yuan, accounting for $12.0 \%$. They want to participate in training, study skills and knowledge, but are relatively cautious in cost investment. 64 people can accept more than 300 Yuan in training cost, accounting for $32 \%$. It can be seen that partial community laborers are willing to pay a certain training fee to receive the training (see "Table $\left.\mathrm{X}^{\prime \prime}\right)$. According to existing researches and the government's training policy in reality, most of the training activities currently carried out in new-type rural communities are free of charge. There is also some training charged but after ending of the training the participated labor force can be compensated accordingly if meeting relevant requirements. Training funds are generally disbursed from government finances and need to be included in the annual budget.

TABLE X. DEMAND FOR TRAINING COST

\begin{tabular}{|l|l|l|}
\hline & \multicolumn{1}{|c|}{ Frequency } & Percentage \\
\hline Not more than 100 Yuan & 112 & 56.0 \\
\hline $101 \sim 300$ Yuan & 24 & 12.0 \\
\hline $301 \sim 600$ Yuan & 55 & 27.5 \\
\hline More than 600 Yuan & 9 & 4.5 \\
\hline Total & 200 & 100.0 \\
\hline
\end{tabular}

\section{CONCLUSION AND POLICY RECOMMENDATIONS}

\section{A. Conclusion}

Analyzing the willingness and demand of labor transfer training in new-type rural communities is an important prerequisite for solving the current problems in community such as mismatched supply and demand and imbalanced supply structure. The state attaches great importance to the training of labor transfer in new agricultural communities, invests many training resources into it, but the training results are not good. There are problems such as mismatched training supply and demand, and the imbalanced supply structure. Only by analyzing these problems and making clear the labor transfer training demand in community can it be available to practically put forward a path to solve the current problems.

Empirical research represented by practical surveys and statistical analysis can help to propose targeted and scientific policy recommendations for labor transfer training in newtype rural community. This study obtained the primary data collected from the field survey in three typical new-type rural communities such as Hongzhou Community, Huazhong Community and Nanbei Community in Qihe County, used SPSS17.0 software and basic description analysis and binary logistic regression model to make a statistical analysis on the willingness and demand of labor forces in new-type rural community for labor transfer training. This makes such suggestion as proposed for solving problems existing in labor transfer training in new-type rural community on the basis of empirical research more argumentative and persuasive.

The top priority of the research should be given to the path or method for solving the problems existing in labor transfer training in new-type rural community. Based on the current practical problems existing in rural labor transfer training and the results of practical survey, this paper provides some policy recommendations for addressing the mismatch of training supply and demand and the imbalance of supply structure from the perspective of conducting practical investigations, increasing capital investment and optimizing the supply structure of training resources and so on.

\section{B. Policy Recommendations}

Based on the current practical problems existing in rural labor transfer training as well as the results of practical survey and domestic and foreign training practice experiences, the following provides some policy recommendations for labor transfer training in new-type rural community.

1) Conducting practical survey: Practical survey is the basis of research. If relevant government departments can make an in-depth investigation and analysis on the community labor training willingness and training needs, it may be helpful to match the training supply with demand and optimize the training supply structure. According to the analysis in this paper, factors such as age, education level, occupation, family annual total income, and whether or not 
they have participated in training have significant impact on residents' willingness to receive the training. Therefore in conducting training mobilization and information propaganda, it is necessary to be targeted, distinguish the difficulty in mobilizing labor forces in different communities, pay attention to the training willingness of different age groups, pay attention to fully mobilize the labor forces having large age, low education level, low family income level and engaging in agriculture, fully publicize relevant training policies and the value and meaning of the training in promoting their income increase and life change and other aspects, add training on agricultural production technology, agricultural management and other aspects and pay attention to the demands of agricultural workforce. For labor forces engaging in industry or project, it is necessary to practically improve their professional skills. Fully developing basic education and improving the education level of labor forces are effective measures for doing well in training in new-type rural communities and help realizing labor transfer. For the laborers who have already participated in the training, it is necessary to go deep into the publicity and mobilization on them so that they can fully understand the specific aspects of the training time, place, content, teachers, forms, employment services, etc., and create them a psychological expectations of good training effect.

2) Increasing capital investment: Training fund is an important material basis for meeting the training needs of new-type rural communities for labor transfer. Foreign governments generally get training funds incorporated in their financial budget and earmark a fund for its specified purpose only. The United States adopts a variety of fiscal appropriation in the form of training grants to support rural labor training. In Germany, the fund for vocational training is included in the financial budget of the country, accounting for $15.3 \%$ of the national education investment. [11] In the training of labor transfer in new-type rural communities, the government's training fund supply should implement administrative gradient financial funds supporting manner. Namely, the training fund for the whole country is allocated as a whole by the central government; the training fund for the provincial administrative region is allocated as a whole by the by provincial governments among local governments; the training fund for the city administrative region is allocated as a whole by the city-level government; and the training fund for the county administrative region is allocated as a whole by the by county-level government. The training funds should be directly allocated to the corresponding training subjects. In this way, the training subjects will be able to obtain funding support from four levels of governments to ensure adequate training funds. Of course, the government may also raise social funds and increase the sources of funds to further enrich the training funds.

3) Optimizing the training supply structure: At present, there are problems in labor transfer training in new-type rural community, such as mismatched supply and demand and imbalanced supply structure. In the future, the training should be targeted to provide training as per the training demands of community labor force.

a) Training content: According to the results of field survey, the demands for content of labor transfer training in the new-type rural community are diversified. Training content should be set as diverse as possible to facilitate community workforce's selection. The training contents are mainly divided into the following four aspects:

- Agricultural production technology and agricultural operation and management training:

Among labor forces in new-type rural community, there are still many laborers engaged in agricultural production. They have the willingness to study scientific and advanced agricultural production techniques to increase crop yields and increase income. There are also many laborers keen on the scale operation of agriculture. They may acquire large amount of land to conduct scaled production so that they are willing to receive training on agricultural production and operation and management.

- Vocational skill training:

Vocational skill training contents can be divided into low-level vocational skills and high-level vocational skills. Low-level vocational skills include beauty salons, general electric welding, chefs, housekeeping services and so on. High-level vocational skills include architectural technical work, clothing design, auto repair and maintenance, electronic instrument operation and so on. The training content of different vocational skill levels should be set as per the different educational level and acceptability of community labor forces.

- Entrepreneurship and enterprise operation and management training:

As can be known from the survey results, people with high education level and income level are more willing to participate in entrepreneurship and enterprise operation and management training. Those labor forces are more open-minded and have relatively high education level. They have broadened their visions from the working experiences and accumulated some funds so that they want to start a business and have their own companies. Therefore, it is very necessary to provide entrepreneurship and enterprise operation and management training.

- Community guiding training:

Guiding training is mainly to provide labor forces in new-type rural communities with training on the common sense of living in community, relevant policy and legal knowledge, cultural quality and so on Guiding training plays an important role in helping community labor forces adapt to the concentrated living in community, protect their legitimate rights 
and interests and promote the transformation of the "citizen" identity.

b) Training method: Based on the single-mode problem in current training and the field research results, the labor transfer training in new-type rural community should focus on practical training, associated by diversified methods. For training contents with high requirement for practical operation ability such as agricultural production technology and vocational skills, the training should focus on practical training in manner that teacher teaches on site or hand by hand and students practically operate. This is beneficial for community labor forces to accept the knowledge learnt and skills mastered. For entrepreneurship and enterprise operation and management and community guiding training, it can be provided in a combination many methods. Depending on the specific situation, it can be taught in classroom or by virtue of Internet or TV.

c) Training cycle: At present, the labor transfer training in new-type rural communities is mostly short-term training so that community labor forces cannot truly learn relevant knowledge and master relevant skills, and the training effect is not good. Therefore in providing the training, the training cycle should be determined on the basis of different training content, difficulty level, and community labor forces' education level. According to the field survey, many respondents indicate that the training time may delay a lot of things, and hope that the training period can be less than three months. In addition, it is available to provide some selections for them such as off-job training or spare-time training on the basis of different training content, difficulty level and community labor forces' acceptance ability. A fixed training place should be set up to carry the training resources and provide a fixed training space for the community labor forces.

d) Training cost: According to the results of field survey, $68 \%$ of the 200 respondents chose training fee less than 300 yuan. Most of the respondents indicate that the training fee is better as low as possible. There are also some respondents willing to receive training of higher training fees. From the current situation, most labor transfer training in new-type rural community is free of charge. Of course, most of the training is carried out at a low level of vocational skills, and the cost of training is also low. Based on the training cost demand of community labor forces, the training cost can be reasonably determined based on the training content and difficulty level. For training with low cost and low vocational skill level, the training can be provided free of charge. And for training with high cost, high vocational skill level and high equipment and facility requirements, the training fees may be charged appropriately.

\section{REFERENCES}

[1] Zhang Jun. Theoretical basis and important role of new-type rural community construction [J]. Rural Economy, 2013(3): 3 6. (in Chinese)
[2] $\mathrm{Xu} \mathrm{Li}$. Evaluation and analysis of new urbanization level and its spatial characteristics - taking Changzhou City of Jiangsu Province as an example [J]. Chinese Journal of Agricultural Resources and Regional Planning, 2018, 39(6): 61 66. (in Chinese)

[3] Adam Smith. The wealth of nations [M]. Newyork: Random House, Inc, 1937: 229.

[4] Schultz T.W. Investment in human capital [J]. American Econimic Review, 1961(51): 1 17.

[5] Revera W.M. The changing nature of agricultural information and the conflictive global developments shaping extension [J]. In:The journal of Agricultural Education and Extension, 2000, 7(1): 31 42.

[6] Paul Bennel. Vocational education and training in Tanzania and Zimbabwe in the context of economic reform. Department for International Development, Education Research Paper[R]. London: Department for International Development, 1999.

[7] Zinnah M.M, Steele R.E, Mattocks D.M. From margin to mainstream revitalization of acultural extension curricula in universities and colleges in sub-Saharan Africa. In:Training for agriculture and rural development 1997-1998[R]. Fao Economic and Social Development, 1998.

[8] Wu Sufang, Wang Yulan. Analysis of supply and demand situation of rural surplus labor transfer training and its countermeasures [J]. China Agricultural Education, 2006(4): 50 52. (in Chinese)

[9] Shi Donghui, Shi Dongmei. Analysis of factors affecting the rural labor transfer training needs of rural area in Ningxia [J]. Journal of Agricultural Sciences, 2014, (35)4: 75 79. (in Chinese)

[10] Pan Guanghui. Training demand and supply of landless farmers: based on investigation and thinking in Guangdong Province [J]. Rural Economy, 2010(10): 108 112. (in Chinese)

[11] Zhou Lihua. Experience and enlightenment from foreign rural labor force vocational skill training $[\mathrm{J}]$. Economic Research Guide, 2016(24): 133 134. (in Chinese) 